\title{
Thinkers needed to improve biventricular assist device outcome
}

\author{
Hiroo Takayama, MD, $\mathrm{PhD}$
}

From the Department of Surgery, Columbia University Medical Center, New York, NY.

Disclosures: Author has nothing to disclose with regard to commercial support.

Received for publication Oct 7, 2016; revisions received Oct 13, 2016; accepted for publication Oct 13, 2016; available ahead of print Dec 7, 2016.

Address for reprints: Hiroo Takayama, MD, PhD, 177 Fort Washington Ave, New York, NY 10032 (E-mail: hirofu2@hotmail.com).

J Thorac Cardiovasc Surg 2017;153:368-9

$0022-5223 / \$ 36.00$

Copyright (c) 2016 Published by Elsevier Inc. on behalf of The American Association for Thoracic Surgery

http://dx.doi.org/10.1016/j.jtcvs.2016.10.030

Previous studies have demonstrated poor survival with biventricular assist device support (BIVAD). Analyses from 3 large multicenter databases show the following survivals with BIVAD versus left ventricular assist device support (LVAD): $68 \%$ versus $93 \%$ at 6 months in the United Network for Organ Sharing registry $(\mathrm{n}=408$ vs $\mathrm{n}=3230),{ }^{1} 50 \%$ versus $80 \%$ at 1 year in the Interagency Registry for Mechanically Assisted Circulatory Support $(\mathrm{n}=358$ vs $\mathrm{n}=11,672){ }^{2}$ and $53 \%$ versus $81 \%$ at 1 year in the International Society for Heart and Lung Transplantation Registry for Mechanically Assisted Circulatory Support $(\mathrm{n}=210$ vs $\mathrm{n}=5509)$.

The study by Bartfay and colleagues ${ }^{4}$ in this issue of the Journal challenges this existing knowledge. Although their patients with BIVAD were sicker, the 1-year survival was $85 \%$, comparable to the $86 \%$ survival of the patients with LVAD. This remarkable accomplishment was attained not only by their strategy of aggressive BIVAD use but also by their thoughtfulness and creativity, which are exemplified by their use of the ROTAFLOW pump (MAQUET Cardiovascular, LLC, Wayne, NJ) with the EXCOR cannulas (Berlin Heart GmbH, Berlin, Germany) during the early postoperative period.

Generalization of their strategy, however, is not so straightforward because of the significant challenges associated with biventricular failure in addition to the limitations of the study, which are well stated in the article. Biventricular failure is commonly declared by the need for BIVAD. Unarguably, BIVAD is used for refractory right ventricular $(\mathrm{RV})$ dysfunction coexisting with left ventricular failure. The clinical presentation of these patients is diverse, with various degrees of hepatorenal dysfunction, lower extremity edema, and ascites, all of which are the result of chronic venous hypertension. The insidious nature of this condition and the lack of a standardized assessment modality for the RV function result in diagnostic and management delays. Cardiac surgeons are familiar with the similar difficulty in severe tricuspid regurgitation and certain congenital heart diseases. In this context, it is not a surprise that the survival is worse with BIVAD than

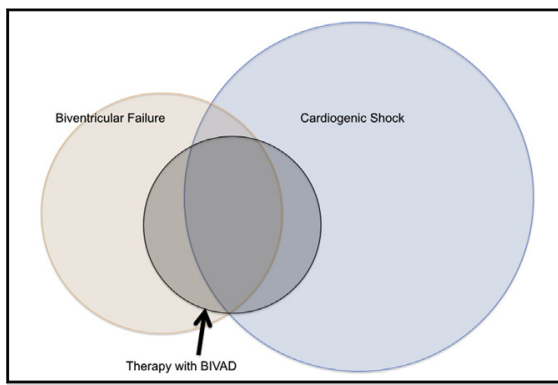

BIVAD therapy is not equal to biventricular failure.

Central Message

BIVAD is used in biventricular failure or cardiogenic shock, and accordingly it has an inferior outcome to LVAD. More thoughts and efforts are required for substantial improvement of BIVAD outcome.

See Article page 360
LVAD, and it also may not be a surprise to see a better BIVAD outcome in less advanced RV failure.

BIVAD is also used in refractory cardiogenic shock regardless of the RV function, and it is probably inappropriate to classify these patients as having biventricular failure (Figure 1). What is clear, however, is that this is the sickest patient population with the worst outcome, and thus it is not a surprise to see a worse outcome with BIVAD.

Finally, we need a revolution in durable continuous-flow RV assist device technology. Going back to pulsatile-flow pumps, as presented in this article, ${ }^{4}$ is unlikely to be a welcome solution unless the expected transplant wait time is short (as it was in this article). Surgeons' contributions (or struggles) to constructing a BIVAD system with the available technologies include total artificial hearts, various configurations of continuous-flow LVAD technology, and continuous-flow LVAD with external or percutaneous RV assist device support. The current strategy in our program at Columbia University Medical Center is first to resuscitate the patient and optimize the patient's condition with minimally invasive external LVAD combined with a percutaneous venous cannula and an oxygenator, providing biventricular support. ${ }^{5}$ This allows the determination of futile cases while minimizing the surgical insult and resource use, as well as providing time for more deliberate assessment of the RV function.

Surgeons should continue to think of how to improve the outcomes of these patients. This is one of the frontiers with opportunities. 


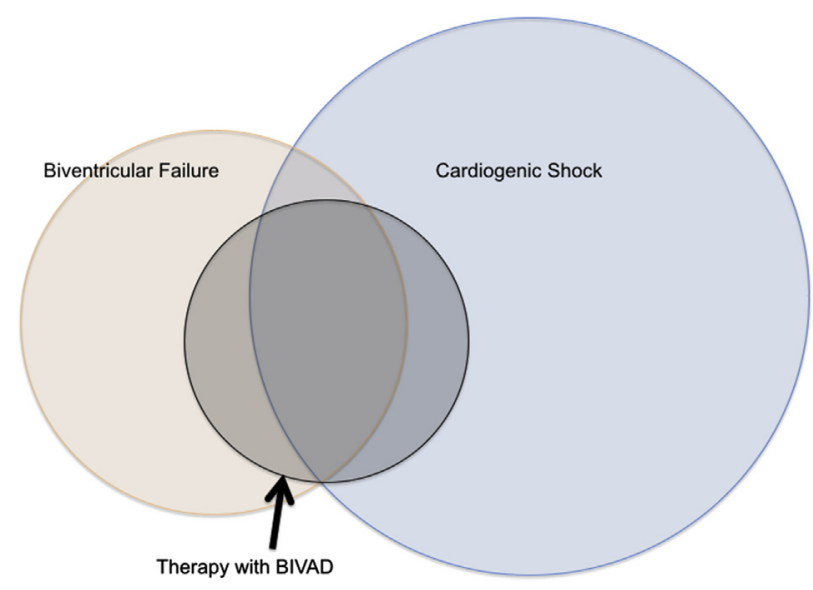

FIGURE 1. Biventricular assist device therapy is not equal to biventricular failure.

\section{References}

1. Levin AP, Jaramillo N, Garan AR, Takeda K, Takayama H, Yuzefpolskaya M, et al Outcomes of contemporary mechanical circulatory support device configurations in patients with severe biventricular failure. J Thorac Cardiovasc Surg. 2016;151: 530-5.e2.

2. Kirklin JK, Naftel DC, Pagani FD, Kormos RL, Stevenson LW, Blume ED, et al Seventh INTERMACS annual report: 15,000 patients and counting. J Heart Lung Transplant. 2015;34:1495-504.

3. Kirklin JK, Cantor R, Mohacsi P, Gummert J, De By T, Hannan MM, et al. First annual IMACS report: a global International Society for Heart and Lung Transplantation registry for mechanical circulatory support. J Heart Lung Transplant. 2016;35:407-12.

4. Bartfay S, Dellgren G, Liden H, Holmberg M, Gabel J, Redfors B, et al. Are biven tricular assist devices underutilized as a bridge to heart transplantation in patients with a high risk of post-implant right ventricular failure? J Thorac Cardiovasc Surg. 2017; 153:360-7.

5. Takeda K, Garan AR, Topkara VK, Kirtane AJ, Karmpaliotis D, Kurlansky P, et al. Novel minimally invasive surgical approach using external ventricular assist device and extracorporeal membrane oxygenation in refractory cardiogenic shock. Eur J Cardiothorac Surg. 2016 [In press]. 